\title{
BIZWATTS: A MODULAR SOCIO-TECHNICAL ENERGY MANAGEMENT SYSTEM FOR EMPOWERING COMMERCIAL BUILDING OCCUPANTS TO CONSERVE ENERGY
}

Gulbinas $\mathrm{R}^{1}$, Jain $\mathrm{RK}^{2}$, Taylor JE ${ }^{3}$

\author{
1,3 Via Dept. of Civil \& Env. Eng. and Myers-Lawson School of Construction, Virginia Tech, Blacksburg, VA, \\ 24061; emails: \{rimasg, jet\}@vt.edu \\ ${ }^{2}$ Center for Urban Science \& Progress, New York University, Brooklyn, NY, 11201; \\ email: rishee.jain@nyu.edu
}

\begin{abstract}
Commercial buildings represent a significant portion of energy consumption and environmental emissions

worldwide. To help mitigate the environmental impact of building operations, building energy management

systems and behavior-based campaigns designed to reduce energy consumption are becoming increasingly

popular. In this paper, we describe the development of a modular socio-technical energy management system,

BizWatts, which combines the two approaches by providing real-time, appliance-level power management and

socially contextualized energy consumption feedback. We describe in detail the physical and virtual architecture of the system, which simultaneously engages building occupants and facility managers, as well as the main principles behind the interface design and component functionalities. A discussion about how the data collection capabilities of the system enable insightful commercial building energy efficiency studies and quantitative network analysis is also included. We conclude by commenting on the validation of the system, identifying current system limitations and introducing new research avenues that the development and deployment of BizWatts enables.
\end{abstract}

Keywords: Behavior Change; Energy Efficiency; Energy Management; Social Networks 


\section{INTRODUCTION}

Buildings are inexorably linked to the environment and economy. In the United States, they are responsible for approximately $41 \%$ [1] of all energy consumed and 40\% [2] of all carbon emitted. Furthermore, $\mathrm{CO}_{2}$ emissions from US buildings are expected to increase faster than any other sector over the next two decades with commercial building emissions projected to grow the fastest, at 1.8\% each year through 2030 [3]. The United States has joined other countries in recognizing the global importance of emission reductions and has set a federal target of reducing national greenhouse gas emissions by $80 \%$ by 2050 [4]. To achieve this ambitious target, myriad public and private initiatives to improve building energy efficiency through technological and regulatory means have emerged [5-10] to facilitate the adoption of a wide array of practical energy efficiency strategies. While strategies based on building retrofits, automation technologies, and behavior-based conservation campaigns are becoming increasingly ubiquitous, initial research has demonstrated that each of these strategies is sensitive to various economic, organizational, and structural factors.

Building retrofits and equipment upgrades, e.g. the installation of more efficient boilers, can significantly improve the energy efficiency of buildings, but are often capital intensive. In addition, purchasing decision-makers often associate high opportunity costs and disproportionately high short-term discount rates with such investments [11], which often fall short due to a split incentive structure in which building owners bear the initial investment costs while commercial tenants benefit from reduced operating costs [12]. Investments in automation solutions, e.g., programmable facility ambient controls, can also improve the efficiency of building systems. However integrated automation strategies can also be cost-prohibitive and have been shown to compromise building occupant comfort [13]. Similar constraints apply to many integrated building energy management systems (BEMS), which provide building operators with information and data visualizations of building system operations and energy consumption. Many of these advanced systems facilitate energy efficiency fault detection by monitoring and processing a range of independent building data-streams, e.g. temperature, energy consumption, weather, solar radiation, lighting, etc., [14]. However, the lack of monitoring hardware interoperability often necessitates the development of custom software interfaces $[15,16]$ that require significant 
domain specific knowledge of building systems to comprehend and analyze. Such systems are therefore difficult to design for casual users and costly to customize and implement in new buildings.

A relatively unobtrusive and economically viable strategy for achieving energy savings in residential and commercial buildings is to motivate energy-conscious behavior among building occupants. However, behaviorbased energy conservation strategies have traditionally suffered from a lack of data granularity and the inability to track the progress of energy reductions over time. For these reasons, commercial buildings have been slower to adopt behavior-based conservation strategies. As building sensing technologies continue to fall in price and become more modular, they will enable the development of new conservation strategies that combine the advantages of BEMS and behavior-based campaigns. New web-based systems that communicate high resolution, real-time energy-use data (i.e. eco-feedback systems) will therefore become increasingly practical.

In this paper, we introduce a novel, advanced eco-feedback system that enables the full potential of building energy-savings to be realized by simultaneously informing the operation of building systems and motivating energy efficient behavior of building occupants. After presenting on-going research efforts on energy efficiency in the built environment, we describe the system's back-end architecture, various interface components, functionalities, and data collection capabilities. We discuss the principles behind the design of the system and finish with a discussion about the types of energy efficiency studies that the system enables, including a summary of results from an initial validation study.

\section{BACKGROUND}

\subsection{Commercial Building Sector Energy Efficiency}

Behavior-based energy conservation campaigns have been shown to cost-effectively achieve significant energysavings in commercial buildings. [17]. Furthermore, simulation models of energy-use in commercial buildings [18, 19] have shown that occupants can have a significant impact on energy-use; a finding which has been supported by behavior-based academic studies $[17,20]$ and industry sponsored energy efficiency initiatives $[21,22]$. In some 
cases, substantial economic benefits have been realized. In an internal group-oriented energy conservation campaign, the United States Postal Service reduced annual operating costs by $\$ 22$ million dollars across 33,000 buildings in 2011. In a separate behavior intervention program, Carrico and Riemer [17] estimated that for every dollar invested in the program, $\$ 32$ dollars in energy costs were saved. Behavior-based energy efficiency strategies also appeal to small firms, of which there are 23 million in the United States - representing up to 34 billion sq. $\mathrm{ft}$. of commercial real estate [23]. Cagno et al. [24] investigated the drivers for adopting energy efficiency technologies and services among small business owners and found that many rated 'information on practices' as more important than 'information on technologies', demonstrating a willingness to adopt low-cost practical solutions that do not require significant financial or technological investment. In order to realize large-scale energy savings, cost-effective systems that help translate 'information on practices' to 'actions that save energy' should be designed for firms and buildings of all sizes.

\subsection{Behavior-based Eco-Feedback Systems}

Behavior based energy efficiency initiatives represent an effective method for achieving significant energy savings but often lack the ability to monitor energy consumption trends at a granular level. Conversely, advanced commercial BEMS tend to monitor energy consumption at a high-resolution but often fail to engage and motivate energy-conscious behavior among building occupants [14-16]. Reconciling the two approaches, research conducted on feedback designed to influence behavior by providing building occupants with various forms of energy consumption feedback (i.e. eco-feedback systems) in residential [25-33] and institutional settings [13, 34] has shown that such systems typically yield energy savings ranging from 5-55\% [35]. In this paper, we introduce BizWatts, a socio-technical energy management system for commercial buildings that combines established social principles of behavior-based energy efficiency initiatives (goal-setting [25, 27, 32], social comparisons [26, 29, 31], team-identity [20]) with high-resolution monitoring and feedback technologies. Our system avoids constraints associated with integrated building management solutions by utilizing a modular plug-load energy monitoring hardware system. This simplifies and adds important flexibility to the system commissioning and decommissioning process and enables a flexible software architecture that can accommodate buildings and organizations of all types and sizes. In addition, BizWatts is designed to simultaneously empower building occupants to save energy and 
utilize them as sources of building information (e.g. occupancy levels), thus reducing the need to rely on disjoint building system monitoring hardware. In 2013, Marinakis et al. [16] stated that, "a system which also includes remote control technology to enable energy end-users to monitor the energy consumption and control the operation of buildings' appliances, as well as optimization functions for the reduction of the energy consumption is required [for better reducing energy consumption]... such an integrated system is not present in the international scientific literature." BizWatts addresses this call by combining near real-time plug load energy data visualization and remote power management at the appliance level with social energy consumption information. It is also designed to extend eco-feedback research to the commercial domain by tracking relevant user-interface and useruser interaction statistics in the form of clickstream data that can be used for analyzing social effects on individual and group energy consumption. The system's architecture, interface features, and design principles are introduced in the following section.

\section{BIZWATTS COMMERCIAL ECO-FEEDBACK SYSTEM}

The BizWatts system is designed to foster a culture of energy efficiency and collaborative engagement in energy conservation activities at the workplace by providing users with various representations of personal and network level energy consumption data. The system was also designed to support controlled high resolution studies on the effects of various energy efficiency interventions (e.g. goal-setting, conservation competitions, incentives) on building occupants by allowing researchers to restrict user access to specific system features and to control which groups of users are exposed to interventions. In this section, we begin by providing a technical illustration of the system's flexible architecture which enables such controlled studies and workplace collaborations. Next, we describe in detail the system's user functionalities, visualizations, and data-mining techniques.

\subsection{BizWatts System Architecture}

BizWatts is a web-browser accessed application built on an Apache/PHP/MySQL platform. As a social energy feedback application, its overall system design is similar to that of its residential predecessor, Watt's Watts [36], and can be summarized by the simplified feedback loop in Figure 1a. From a high level perspective, energy data collected by plug-load energy monitors is pushed to a server where it is processed and fed to the BizWatts 
application. The BizWatts application is accessed by building occupants who interact with one another by comparing energy consumption information and actions and discussing conservation strategies over the application. This network level feedback has been shown to motivate building occupants to conserve energy [30] and is intended to encourage closer monitoring of plug-load (and potentially shared resource, e.g. lighting, HVAC) energy consumption. Changes in behavior are reflected by updated energy consumption data visualizations, thereby closing the feedback loop and allowing building occupants to continue the collaborative learning and energy conservation process.

Energy data is captured by commercially available wireless plug load power monitors, which also enable users to remotely turn on/off assigned appliances. Each power monitor wirelessly communicates an appliance's power information via $900 \mathrm{MHz}$ RF signal to an edge router that uploads data to a database via Ethernet connection. Time, location, device identification, real power (W), current (A), voltage (V), and power factor data are pushed through the router every 15 minutes to a database hosted on an external server and managed by the People Power Company. The BizWatts system allows up to 12 standard North American 120V appliances (computers, fans, space heaters, etc...) to be assigned to individual users and collects energy data for each appliance independently. With open-API access to the server that holds the energy-use data, BizWatts performs nightly migrations of user energy data to an independent database where the data is stored and parsed to optimize the load times of historical energy consumption visualizations over days, weeks, and months. While aggregated historical energy information is retrieved from the BizWatts server, same day power and energy information is retrieved directly from the primary external server to decrease load times. In addition to collecting, processing, and communicating high-resolution energy-use feedback, BizWatts also monitors user interactions with the software interface. This clickstream data is used for analyzing several topics of interest, including: when and which users login to the system, which interface components are used the most often, and what actions users are adopting to conserve energy. Collecting this information enables a quantitative approach to system interface improvement that will be discussed later in this paper. A detailed schematic representing the system's design and data flow can be viewed in Figure 1b. 
Insert Figure 1 approximately here

\subsection{System Initialization}

To maximize its applicability to various organizational structures and commercial buildings, BizWatts was designed to support flexible group configurations. Once individuals are registered in the database and assigned to specific plug-load monitoring devices as described in section 3.1, system administrators can create organizational groups to which individuals may be added. When an individual is assigned to a group, a series of group-spanning metrics are calculated, such as the group's total and per capita energy consumption over various time periods and appliance types, in order to facilitate meaningful group energy use comparisons. If an individual changes groups, the system recalculates these metrics and updates group statistics in order to eliminate potential data redundancy. BizWatts supports large organizations with multiple layers of groups (e.g. groups within a department, departments within a corporation) in a child-parent structure as seen in the bottom-right of Fig. $\mathbf{2}$, as well as smaller firms with flat organizational structures. System administrators can define group settings and manage the overall organizational structure using the group management screen observed in Fig. $\mathbf{2}$. 
Insert Figure 2 approximately here

When groups are established, a host of additional user and administrative features become available:

1) Members gain access to visualizations of other groups' normalized energy consumption data in addition to their own. This facilitates competition between groups through meaningful group vs. group comparisons.

2) Each group can be assigned a specific energy-use reduction goal relative to a baseline period average, which is displayed on each group member's energy plots. This helps establish group identity and motivates cooperation to achieve the conservation goal.

3) Each group can be assigned a leader, whose energy consumption is overlaid on members' energy graphs. This encourages group leaders to motivate members through their own conservation actions.

4) System administrators can manage the ability of members to remotely control the power states of their appliances at the group level. This prevents accidental power disruptions of sensitive equipment.

The settings of each group, as managed by a system administrator, also define the types of visualizations that are made available to users.

\subsection{Visualizations}

BizWatts was designed as a social energy feedback system that facilities individual and collaborative learning around high-resolution, high-frequency feedback. A central navigation bar located in the header of the userinterface controls the core visualization tool and enables users to toggle between combinations of individual, group, social, and appliance-based representations of energy consumption. In addition to toggling between the 
feedback representations presented in Table 1, users can select the time unit (e.g. 'Today', 'Weekly', and 'Monthly') over which they would like their appliance, individual or group-level energy data to be aggregated.

Insert Table 1 approximately here

\subsubsection{Energy-use Comparisons}

The ability to share energy use information among building occupants was demonstrated to significantly impact network-level energy conservation behavior in residential studies [30, 37]. BizWatts was designed to leverage such observed network dynamics in commercial buildings, by encouraging users to share as much energy related information as possible over a simple, intuitive interface. In the comparison graph tool in Fig 3(a), users are able to simultaneously overlay the energy consumption data of up to 8 users over various time intervals. In addition to being able to make energy-use comparisons with others in their organizational networks, users can also manage an ad-hoc social group consisting of personally selected 'friends' from across their entire organization. 
Insert Figure 3 approximately here

The checklist below the 'My Energy Savings' box in Fig. 3(a) contains a list separating individuals in a user's organizational and social groups, from which users can select other users with whom to compare energy use. Users can also choose to compare historical data by selecting past time intervals in the 'Time Frame' dropdown menu below the comparison plot. The dotted line in Fig. 3(a) reflects a performance goal set by a system administrator that is based on a percent reduction applied to the user's average baseline performance ${ }^{1}$. The blue 'My Energy Savings' box in the top left corner of Fig. 3(a) represents the actual percent difference between the total consumption of the user over the selected time frame relative to average baseline levels, as determined by

\section{Equation 1:}

$$
\text { (1) } \quad \delta_{\text {period }}=\left(E_{\text {baseline }}-E_{\text {period }}\right) / E_{\text {baseline }}
$$

where $E_{\text {period }}$ is the total energy consumption of a user or group over the selected day, week, or monthly period and Ebaseline is the average daily energy consumption of a user or group over a baseline period multiplied by the number of days in the user-selected time period. These tracking features allow users to assess their performance relative to a defined goal, which White [38] showed to have a positive impact on employee productivity. Furthermore, users can compare energy efficiency savings with other users in the ranking view in Fig. $\mathbf{3}(\mathbf{b})$ that is initialized by toggling to the 'Top Savers' mode in the blue 'My Energy Savings' box. Ranking boards have been observed to be the most popular features in other social systems designed to motivate conservation [39]. BizWatts incorporates a ranking

\footnotetext{
${ }^{1} \mathrm{~A}$ user's baseline performance is defined as a user's average energy use during a period before the BizWatts system was initiated.
} 
board to allow users to benchmark themselves against others in their network relative to their respective baseline usage.

In organizations that consist of multiple groups, users can toggle to group-based representations of feedback. The ability to compare performance at a group-level was demonstrated by Siero et al. [20] to help build team identity and foster collaboration, ultimately leading to increased levels of energy conservation. In the BizWatts group comparison view, users can track and compare their group's per capita energy-use over time with the per capita energy-use of other groups, facilitating meaningful comparisons between groups of varying sizes. In addition to these group-level energy-use comparisons, the 'My Energy Savings' box changes to reflect the group's performance relative to its baseline consumption levels and the ranking board displays energy savings for each group, rather than each individual. In this way, the entire core visualization tool is updated to reflect a group-level perspective.

\subsubsection{Appliance Energy-Use Breakdowns}

To complement energy-use comparisons between individuals and groups, we developed an appliance breakdown tool that allows users to independently learn the relative consumption levels of appliances under their control. The development of this tool was motivated by several energy efficiency program studies that demonstrated the utility of appliance-level feedback $[39,40]$, as well as Fischer's review of eco-feedback studies [27] that affirmed the importance of interface tools that draw a direct link between specific actions and consumption. The appliance breakdown tool, observed in Fig. 4, shows the relative energy consumption of all appliances assigned to a user over a time period selected by the user. The tool helps individuals and groups identify appliances that may be being left powered on or used inefficiently, enabling conservation actions to be targeted to specific appliance types. It also allows users to compare appliance energy breakdowns with other users to learn how top energy savers in their network consume energy. 
Insert Figure 4 approximately here

\subsubsection{Eco-Action Center}

In order to encourage collaborative conservation strategies, an Eco-Action Center was designed that allows users to share and discuss sustainable practices and to report conservation actions that are not captured by the plugload energy monitors. The Eco-Action Center, the condensed version of which can be viewed in Fig. 5(a), complements the aforementioned feedback visualizations with a forum where users can explicitly establish and adopt energy efficiency strategies around sustainability-oriented actions.

Insert Figure 5 approximately here

The Eco-Action Center allows organizations to discover the most popular energy efficiency actions among their employees. Conservation action posts created by users are displayed across the entire organizational network where others can 'like', 'comment', or 'check' them. Individuals click: the thumbs-up symbol next to a post to 
express that they 'like' the post, the text bubble if they would like to leave a comment regarding the post, and the checkmark symbol to self-report when they complete a specific conservation action. The default view of the EcoAction Center lists posts according to when they were most recently engaged ('liked', 'commented', or 'checked') by users in the organization but users can also filter posts according to popularity, which is determined by an algorithm that assigns weights to the number of likes, comments, and checks that each action receives. New post creation and popularity growth are monitored by the system and allow system administrators to identify the most regular actions taken by employees. As the number of self-reported 'checks' is tracked, users can also compare their activity with others in their network by using the action comparison tool in Fig. $\mathbf{5 ( b ) . ~ T h e ~ s t a t i c ~ l i s t ~ o f ~ a c t i o n s ~}$ in Fig. $\mathbf{5 ( b )}$ is managed by a system administrator, who can select the most relevant set of actions for a specific group and prioritize actions that are more relevant to the organization's sustainability goals. The user-generated nature of the conservation posts ensures their relevancy to the physical setting of the users, which Grevet et al. [39] showed to be important for motivating behavior change.

\subsection{Data Mining and Analysis}

BizWatts was designed to collect data from a range of sources that could be used to form rich insights into building occupant behavior and energy-use patterns. These insights can, in turn, inform the design of more engaging eco-feedback interfaces and provide a better understanding of organizational network dynamics in energy conservation initiatives.

\subsubsection{Clickstream Data}

Clickstream data can be used to quantitatively assess levels of user engagement with software interface components [42-44]. As user engagement with eco-feedback software systems has been found to be positively correlated with energy savings [28], it is important to design such systems to maximize levels of user engagement. BizWatts therefore collects clickstream data pertaining to user interactions with a number of interface components to enable meaningful engagement analysis. A diagram demonstrating the relationship between energy-use and user-interface data processing can be observed in Figure 1b. This clickstream data is stored in a database that is continually updated with new activity and can be queried to facilitate clickstream data analysis for 
identifying underutilized components for redesign or replacement. The clickstream data points collected by BizWatts, along with all the other types of data collected by the system, are listed in Table $\mathbf{2}$.

Insert Table 2 approximately here

Beyond being used to quantify levels of user engagement with interface components, clickstream data can be combined with other data types to provide additional insights. Time-stamped clickstream data can be matched with plug-load energy-use data to investigate temporal relationships between interface interactions and actual energy conservation [30]. By further combining this matched data with information on organizational network structure, analysis can be extended to quantify the level of influence a user has on a network's energy consumption behavior [45] and the impacts of organizational network connections on energy conservation. As BizWatts was initially designed as a research tool, a range of administrative group management functions were built into the system to facilitate controlled studies designed to isolate the effects of user engagement and organizational network dynamics. These functions, combined with clickstream and energy-use data, enable scientific research into the impact of different energy conservation strategies (e.g. goal-setting, hierarchical comparisons, network collaboration, user-rankings) in commercial buildings.

\subsection{Discussion}

\subsubsection{An Eco-Feedback System for Building Occupants}

The BizWatts system represents a novel approach to energy management in commercial buildings that complements existing commercial BEMS by monitoring and communicating individual and appliance-level energy- 
use data that often falls beyond the scope of traditional BEMS. Building off previous research involving the development of residential building social eco-feedback systems [36], BizWatts connects building occupants through organizational and social networks to facilitate collaboration and competition to achieve energy efficiency goals. This approach, coupled with the modularity of the system's monitoring architecture, allows BizWatts to directly incorporate building occupants into the building energy-use feedback loop. The engagement of building occupants is a novel approach enabled by the BizWatts system that has traditionally fallen outside the scope of commercial BEMS [14-16, 46-47], due to technological and organizational constraints. Answering the call by Marinakis et al. [16] to enable user remote control and optimization functions, BizWatts provides a platform that simultaneously enables user remote control of connected appliances and captures high-resolution energy consumption data that can inform behavior-based energy efficiency strategies. Furthermore, the flexibility of the system architecture allows BizWatts to support a wide range of organizational structures, from small businesses to

large, multi-department organizations. Organizational structures vary substantially across businesses and the BizWatts system was designed to accommodate such variability.

In addition to facilitating a bottom-up organizational approach to commercial building energy efficiency, BizWatts contributes to dialogue regarding eco-feedback design $[28,48]$ and feedback efficacy [26-27] through its ability to collect data that enables internal design and external impact validation. Collected clickstream data enables a continuous interface improvement process aimed at maximizing user engagement, thus facilitating internal design validation. In addition, collected energy-use data for a predefined baseline period can be compared with consumption patterns after users are given access to the system in order to determine the effectiveness of the system in driving energy conservation [50]. By combining energy-use data with clickstream and organizational network data, the impacts of group collaboration and competition can also be evaluated. Furthermore, this enables BizWatts to inform commercial building occupant energy use behavior [18-19, 49] simulations by collecting individual occupant level data that can be used to effectively calibrate model parameters.

\subsubsection{Pilot Study and System Validation}

Unlike existing commercial building energy management systems, BizWatts helps commercial building occupants and operators save energy by presenting engaging energy feedback visualizations that motivate and inform 
efficient energy use behavior. BizWatts also collects a range of data that facilitates interface design improvements and scientific research into the impacts of various energy efficiency strategies. This combined applied and research-oriented approach allows BizWatts to go beyond what can be achieved by traditional energy efficiency strategies. In an initial pilot study designed to validate the design principles around which the BizWatts system was built, organizationally connected building occupants each conserved approximately $50 \mathrm{Wh} /$ day in plug-load electricity relative to a control group (no exposure to feedback) and their own baseline levels, at a statistically significant level of $p<0.05$. Furthermore, over 600 clickstream data points reflecting user interactions with interface components were collected, which have been analyzed to determine which components of the system were underutilized and can be improved. Of these data points, 124 were self-reported conservation actions from occupants who actively engaged in the management of energy intensive shared resources that were not captured in the electricity data collected by the BizWatts system. Examples of reported actions include: taking the stairs instead of the elevator, turning off common and bathroom lights, and taking a bike or public transportation to work. BizWatts is designed to establish and leverage a link between individual action and energy conservation in order to motivate increased shared resource management, translating into substantially more energy savings than can be achieved by managing plug-loads alone. While the system will evolve to monitor energy-use of shared resources, the pilot study confirmed that individuals who interact with the system are indeed inclined to save energy and engage with the interface to self-report active conservation actions-a positive indication that including additional shared resource monitoring will provide value to building occupants.

\subsubsection{Limitations}

BizWatts is designed to motivate behavior change by leveraging the power of social norms, appliance-specific feedback, and collaborative learning. However, the system is currently limited by its physical capacity to monitor only appliance plug loads. As such, energy consumption data related to shared resources such as lighting, central heating and cooling, and hot water is not captured. However, as building system monitoring and control technologies continue to drop in cost, additional feedback data streams will be integrated into the BizWatts system, enabling further research into the effects of additional data streams on occupant behavior. Furthermore, while correlations between floor level energy consumption and user engagement with the Eco-Action Center can 
be investigated, disaggregation of the energy data by specific resource is not currently possible without the utilization of additional sub-metering equipment. This limitation makes it difficult to disaggregate the total energy savings due to behavior change and to tie specific Eco-Action Center interactions to these savings. However, ecoaction center data can be used to determine which conservation actions were the most popular among users, which can be used to indirectly estimate the proportion of total energy savings attributed to each type of action when conducting analysis on total shared resource energy consumption change. In addition, as building energy data becomes more standardized [8], it will become more economical to directly incorporate sub-metered energy data streams into eco-feedback systems like BizWatts and additional spatial efficiency analysis will be enabled.

\subsubsection{Future Development}

The results of an initial pilot study [50] indicate that BizWatts can successfully motivate commercial building occupants to reduce energy consumption, thus validating the network principles behind the system's design. In the study, building occupants were provided varying access to individual and network-level energy-use data through the eco-feedback system, as described in Section 3.3, and user-interface interactions (e.g. logins, energy-use comparisons, and shared communications) were recorded. The study demonstrated that exposure to individual energy feedback did not result in significant energy savings, while exposure to network level eco-feedback did induce statistically significant building occupant energy savings. While the study served to validate the network principles upon which the system was designed, it also collected data that could be used to improve the interface. Following the methodology proposed by Jain et al. [28], which demonstrated that user-interface analyses can be used for design improvement, initial analysis of collected clickstream data revealed that building occupants connected over the system interacted much more frequently with the system than those who were only exposed to individual feedback. Furthermore, some interface features, such as the commenting capabilities in the EcoFeedback section and the ability to add more 'friends' (Section 3.3), were discovered to be largely under-utilized during the study. Future development of the system will therefore be focused on improving the user-experience of these system features in order to increase levels of engagement.

Large, instantaneous changes in individual energy consumption can reflect occupancy levels, allowing the BizWatts system to detect when an individual arrives to their desk. The ability to detect, and with enough data 
points, predict occupancy levels in specific physical locations of a commercial building with a high degree of accuracy can lead to multiple energy efficiency improvements. The information can be used to optimize the operation of HVAC systems, which account for nearly $43 \%$ of the energy consumption of commercial buildings [1]. Machine learning algorithms to predict what time of day individuals arrive to a building based on their individual energy-use patterns, which are currently being developed by the authors, can inform the ideal operation schedules of HVAC systems. Furthermore, derived occupancy data can also be used to optimize spatial utilization in commercial buildings. By identifying areas in a building that are underutilized (or over-utilized), office spaces can be reconfigured to provide a more efficient work environment based on an organization's needs. The authors plan to integrate the ability to predict occupancy levels and communicate this information to relevant users in future versions of BizWatts.

\subsubsection{Future Research Avenues}

The results of a BizWatts system pilot study [50] have indicated that organizational networks can have a significant impact on energy conservation. As BizWatts evolves to support much larger and more complexly structured organizations, it will become possible to investigate hierarchical pressures on network-level energy consumption and differences in network effects that may arise at varying organizational sizes. It will also be possible to install BizWatts across multiple organizations to study how influence may extend across networks of independent organizations of various types and sizes, thus helping inform large-scale regional load shedding strategies.

Beyond the organizational network dynamics and eco-feedback interface studies, the BizWatts system could be used to investigate the diffusion of energy conservation actions through organizational networks and the effects of combining advanced eco-feedback with goal-setting and hierarchical influences. These studies stand to contribute significantly to research efforts on the design of the most effective organizational energy efficiency policies.

\subsection{Conclusion}

BizWatts was developed to enable research into how organizational and social networks at the workplace behave when goal-setting, normative comparisons and user rankings are combined with high-resolution, high- 
frequency energy feedback. BizWatts effectively incorporates modularity in processes related to hardware commissioning, data collection, and building occupant group management and is based on portable, wireless plugload energy monitoring technology that offers several advantages over circuit-integrated systems. First, the flexibility associated with the installation of the plug-load monitors allows them to be assigned to specific plugs and individuals in a building. They can be easily reassigned to other occupants and their installation does not interfere with other building systems. Furthermore, the hardware enables users to remotely control connected appliances [16] while collecting high-resolution energy-use data, which enables the determination and prediction of additional proxy measures, such as building occupancy and occupant energy-use efficiency.

Beyond supporting a modular energy-monitoring network, the software architecture also supports a wide range of organizational structures, which can vary highly from small businesses to large, multi-department organizations. Through BizWatts, individuals can share and compare energy-use and reported conservation action information. Sharing capabilities are determined by system administrators who can set software permissions that follow flat, hierarchical, and distributed organizational structures.

By combining high-resolution modular hardware with flexible software architecture, customizable energy efficiency campaigns are enabled for a wide variety of commercial building environments. To aid in energy-use and user-interface interaction analysis, extensive clickstream data collection capabilities were incorporated into the underlying BizWatts architecture. Collected clickstream data enables a continuous interface improvement process for maximizing user engagement and facilitates analysis related to how building occupants interact with one another over the system. . The development of the BizWatts system represents an integral step towards deepening our understanding of the dynamics at the intersection of the human and built environment necessary for realizing substantial energy consumption reductions in commercial buildings.

\subsection{Acknowledgments}

This material is based upon work supported by the Department of Energy Building Technologies Program and the National Science Foundation under Grant No. 1142379. Any opinions, findings, and conclusions or recommendations expressed in this material are those of the authors and do not necessarily reflect the views of 
the Department of Energy or the National Science Foundation. The authors would like to thank the Alliance for Sustainable Colorado for helping test the BizWatts system and providing invaluable feedback regarding its design.

\subsection{References}

[1] US Department of Energy (2010) "Buildings Energy Data Book" <http://buildingsdatabook.eere.energy.gov/> (Sep. 1, 2012)

[2] Energy Information Agency (2009) "Emissions of Greenhouse Gases in the United States Report" <http://www.eia.gov/environment/emissions/ghg_report/pdf/tbl3.pdf> (Sep. 1, 2013)

[3] US Green Buildings Council (2007) "Buildings and Climate Change Document" $<$ www.usgbc.org/ShowFile.aspx?DocumentID=5033> (Sep. 1, 2013)

[4] United States White House (2012) "Administration Announces New Tools to Help Consumers Manage Electricity Use and Shrink Bills"

<http://www.whitehouse.gov/administration/eop/ostp/pressroom/01182012> (Oct 1,2013)

[5] US Green Buildings Council (2013) "LEED Rating Systems" <http://www.usgbc.org/leed/certification> (Oct. 16, 2013)

[6] RESNET (2013) “Mortgage Industry National Home Energy Rating Standards" <http://www.resnet.us/professional/standards/mortgage> (Oct. 16, 2013)

[7] US Environmental Protection Agency (2013) “Energy Star Program" <http://www.energystar.gov/> (Oct. 16, 2013)

[8] US Green Button Initiative (2013) "About Green Button" <http://www.greenbuttondata.org/greenabout.html> (Oct. 16, 2013)

[9] ASHRAE (2013) "Official Website of ASHRAE SSPC 135" <http://www.bacnet.org/> (Oct. 16, 2013)

[10] International Organizations for Standardization (2013) “ISO 50001 - Energy Management" <http://www.iso.org/iso/home/standards/management-standards/iso50001.htm> (Oct. 16, 2013)

[11] Wilson C, Dowlatabadi H. Models of Decision Making and Residential Energy Use. Annual Review of Environment and Resources 2007; 32(1), 169-203.

[12] Randazzo KV, Peters JS. Reconsidering What We Measure: A White Paper. Opinion Dynamics Corporation, Waltham, MA; 2011.

[13] Krioukov A, Dawson-haggerty S, Lee L, Rehmane O, Culler D. A Living Laboratory Study in Personalized Automated Lighting Controls. Proceedings of the Third ACM Workshop on Embedded Sensing Systems for Energy-Efficiency in Buildings; 2011; Seattle, WA: ACM; 2011. p. 1-6.

[14] Costa A, Keane MM, Torrens JI, Corry E. Building operation and energy performance: Monitoring, analysis and optimisation toolkit. Applied Energy 2013; 101, 310-316.

[15] Swords B, Coyle E, Norton B. An enterprise energy-information system. Applied Energy 2008; 85(1), 6169.

[16] Marinakis V, Doukas H, Karakosta C, Psarras J. An integrated system for buildings' energy-efficient automation: Application in the tertiary sector. Applied Energy 2013; 101, 6-14.

[17] Carrico AR, Riemer M. Motivating energy conservation in the workplace: An evaluation of the use of group-level feedback and peer education. Journal of Environmental Psychology 2011; 31, 1-13.

[18] Azar E, Menassa C. Agent-based modeling of occupants and their impact on energy use in commercial buildings. Journal of Computing in Civil Engineering 2011; 26.4: 506-518. 
[19] Azar E, Menassa C. A comprehensive analysis of the impact of occupancy parameters in energy simulation of office buildings. Energy and Buildings 2012; 55: 841-853.

[20] Siero FW, Bakker AB, Dekker GB, Van Den Burg MTC. Changing organizational energy consumption behaviour through comparative feedback. Journal of Environmental Psychology 1996; 16(3), 235-246.

[21] United States Postal Service (2012) "Postal Service Saves Millions in Energy Costs" <http://about.usps.com/news/national-releases/2012/pr12_097.htm> (Nov. 13, 2012)

[22] Starbucks (2012) "Energy Conservation" <http://www.starbucks.com/responsibility/environment/energy> (Oct. 1, 2013)

[23] United States Small Business Administration (2013) "Small Business Trends" <http://www.sba.gov/content/small-business-trends> (Oct. 1, 2013)

[24] Cagno E, Trianni A. Exploring drivers for energy efficiency within small- and medium-sized enterprises: First evidences from Italian manufacturing enterprises. Applied Energy 2013; 104, 276-285.

[25] Abrahamse W, Steg L, Vlek C, Rothengatter T. The effect of tailored information, goal setting, and tailored feedback on household energy use, energy-related behaviors, and behavioral antecedents. Journal of Environmental Psychology 2007; 27(4), 265-276.

[26] Allcott H. Social norms and energy conservation. Journal of Public Economics 2011; 95(9-10), 10821095.

[27] Fischer C. Feedback on household electricity consumption: a tool saving energy? Energy Efficiency 2008; 1(1), 79-104.

[28] Jain RK, Taylor JE, Peschiera G. Assessing eco-feedback interface usage and design to drive energy efficiency in buildings. Energy and Buildings 2012; 48, 8-17.

[29] Nolan JM, Schultz PW, Cialdini RB, Goldstein NJ, Griskevicius V. Normative Social Influence is Underdetected. Personality and Social Psychology Bulletin 2008; 34(7), 913-923.

[30] Peschiera G, Taylor JE, Siegel JA. Response-relapse patterns of building occupant electricity consumption following exposure to personal, contextualized and occupant peer network utilization data. Energy and Buildings 2010; 42(8), 1329-1336.

[31] Petersen JE, Shunturov V, Janda K, Platt G, Weinberger K. Dormitory residents reduce electricity consumption when exposed to real-time visual feedback and incentives. International Journal of Sustainability in Higher Education 2007; 8(1), 16-33.

[32] Seligman C, Darley JM, Becker LJ. Behavioral approaches to residential energy conservation. Energy and Buildings 1978; 1(3), 325-337.

[33] Ueno T, Sano F, Saeki O, Tsuji K. Effectiveness of an energy-consumption information system on energy savings in residential houses based on monitored data. Applied Energy 2006; 83(2), 166-183.

[34] Jiang X, Van Ly M, Taneja J, Dutta P, Culler D. Experiences with a high-fidelity wireless building energy auditing network. Proceedings of the 7th ACM Conference on Embedded Networked Sensor Systems; 2009; Berkeley, CA: ACM; 2009. p. 113-126.

[35] Dietz T, Gardner GT, Gilligan J, Stern PC, Vandenbergh MP. Household actions can provide a behavioral wedge to rapidly reduce US carbon emissions. Proceedings of the National Academy of Sciences 2009; 106(44), 18452-18456.

[36] Gulbinas R, Jain R, Taylor JE, Peschiera G, Golparvar-Fard M. Network Eco-Informatics: Development of a Social Eco-Feedback System to Drive Energy Efficiency in Residential Buildings. ASCE Journal of Computing in Civil Engineering 2013; 10.1061: 1943-5487 
[37] Peschiera G, Taylor JE. The Impact of Peer Network Position on Electricity Consumption in Building Occupant Networks Utilizing Energy Feedback Systems. Energy and Buildings 2012; 49: 584-590.

[38] White SE, Mitchell TR, Bell CH. Goal Setting, Evaluation Apprehension, and Social Cues as Determinants of Job Performance and Job Satisfaction in a Simulated Organization. Journal of Applied Psychology 1977; 62(6), 665-673.

[39] Foster D, Lawson S, Blythe M, Cairns P. Wattsup?: Motivating reductions in domestic energy consumption using social networks. Proceedings of the 6th Nordic Conference on Human-Computer Interaction: Extending Boundaries; 2012; Reykjavic, Iceland: ACM; 2012. p. 178-187.

[40] Petkov P, Köbler F, Foth M, Krcmar H. Motivating domestic energy conservation through comparative, community-based feedback in mobile and social media. Proceedings of the 5 th International Conference on Communities and Technologies; 2011; Brisbane, Australia: ACM 2011. p. 21-30.

[41] Grevet C, Mankoff J, Anderson SD. Design and evaluation of a social visualization aimed at encouraging sustainable behavior. Proceedings of 43rd Hawaii International Conference on System Sciences; 2010; Honolulu, HI: IEEE Computer Society; 2010. p. 1-8.

[42] Benevenuto F, Rodrigues T, Cha M, Almeida V. Characterizing user behavior in online social networks. Proceedings of the 9th ACM SIGCOMM conference on Internet measurement; 2009; Chicago, USA: ACM 2009. p. 49-62.

[43] Das R, Turkoglu I. Creating meaningful data from web logs for improving the impressiveness of a website by using path analysis method. Expert Systems with Applications 2009; 36(3), 6635-6644.

[44] Srivastava T, Desikan P, Kumar V. Web mining-concepts, applications and research directions. Foundations and Advances in Data Mining 2005; 180(2005), 275-307.

[45] Jain R, Gulbinas R, Taylor JE, Culligan P. Can Social Influence Drive Energy Savings? Detecting the Impact of Social Influence on the Energy Consumption Behavior of Networked Users Exposed to Normative Eco-feedback. Energy and Buildings 2013; 66: 119-127.

[46] Cisco EnergyWise (2013) "Cisco EnergyWise Technology - Cisco Systems" <http://www.cisco.com/en/US/products/ps10195/index.html> (Oct. 1, 2013)

[47] JouleX (2013) “Enterprise Energy Management” <http://www.joulex.net/> (Oct. 1, 2013)

[48] Froehlich J, Findlater L, Landay J. The design of eco-feedback technology. Proceedings of the 28th international conference on Human factors in computing systems; 2010; Atlanta, USA: ACM; 2010. p. 1999-2008.

[49] Chen J, Jain R, Taylor JE. Block Configuration Modeling: A Novel Simulation Model to Emulate Building Occupant Peer Networks and their Impact on Building Energy Consumption. Applied Energy 2013; 105: 358-368.

[50] Gulbinas R, Taylor J. Effects of Organizational Network Dynamics on Energy Consumption in Commercial Buildings. In Proceedings of the 8th Conference on Sustainable Development of Energy, Water and Environment Systems; 2013; Dubrovnik, Croatia: ISSN 1847-7178. 


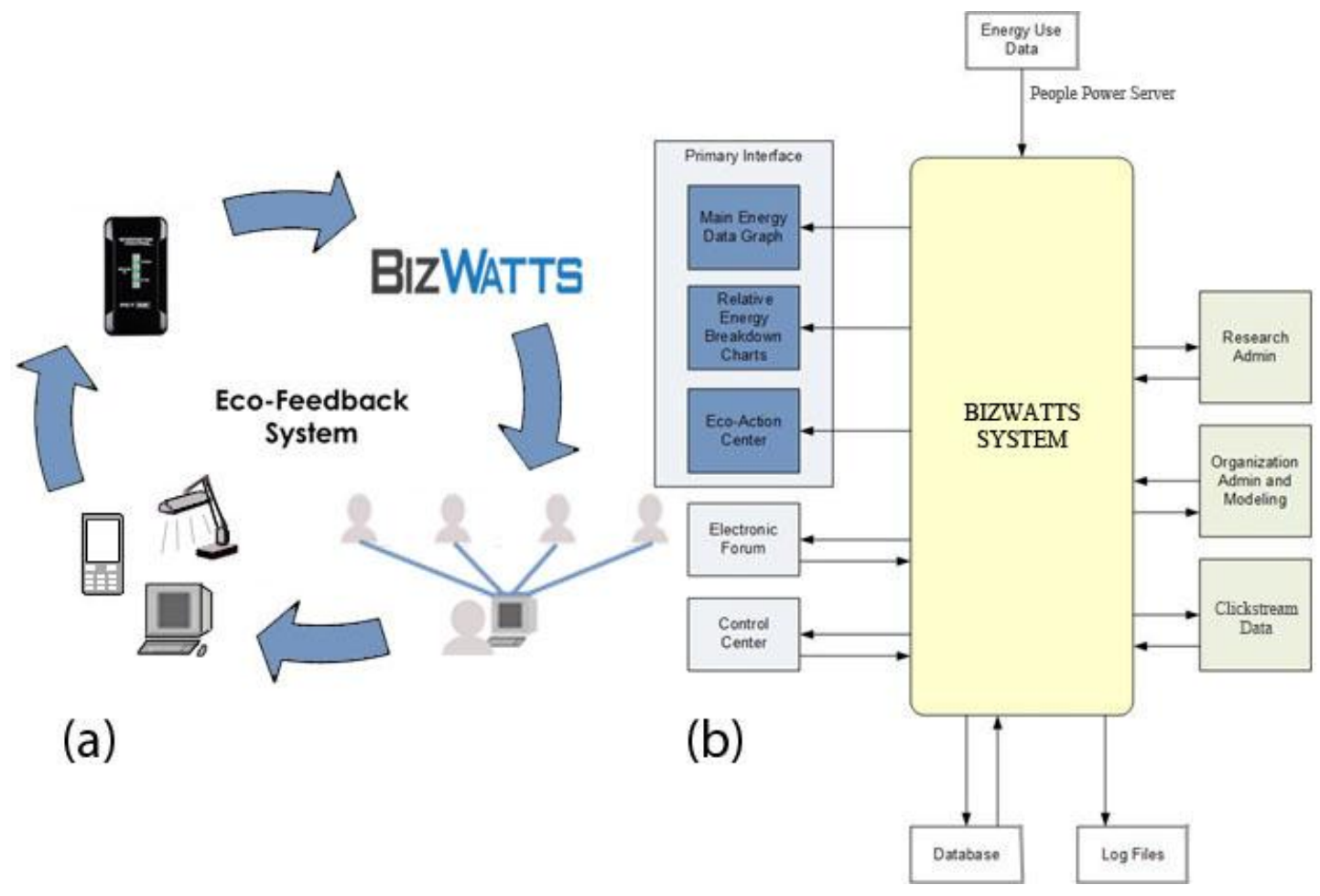




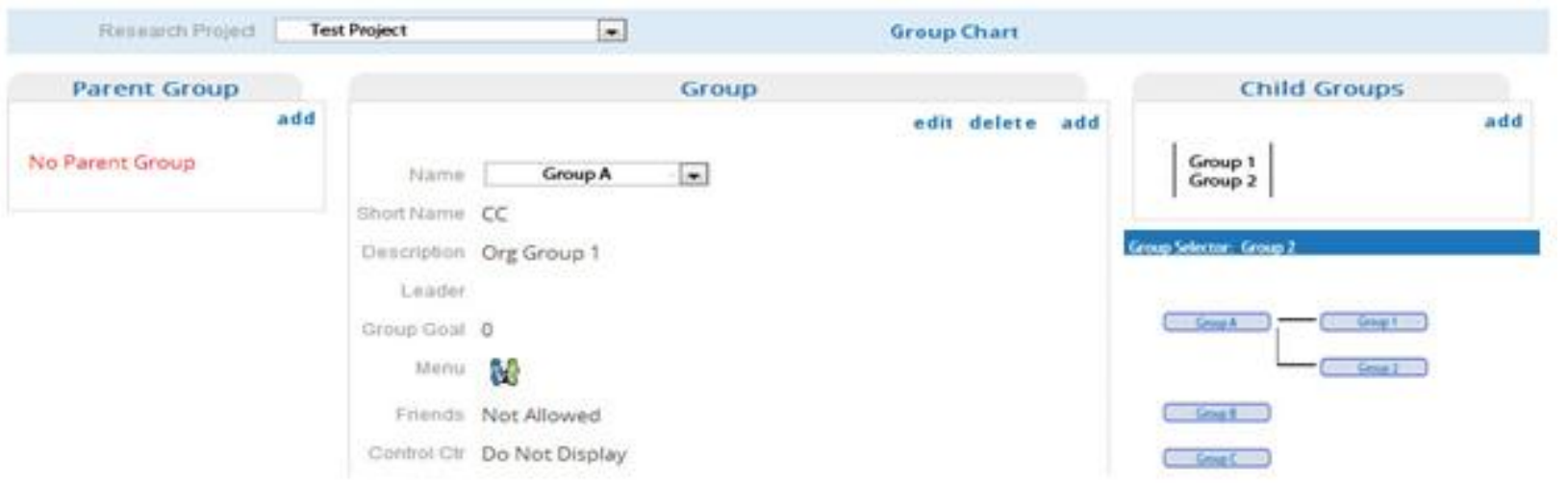


(a)

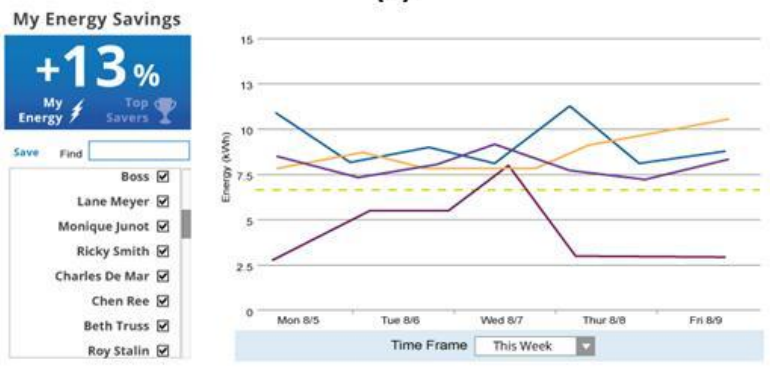

(b)
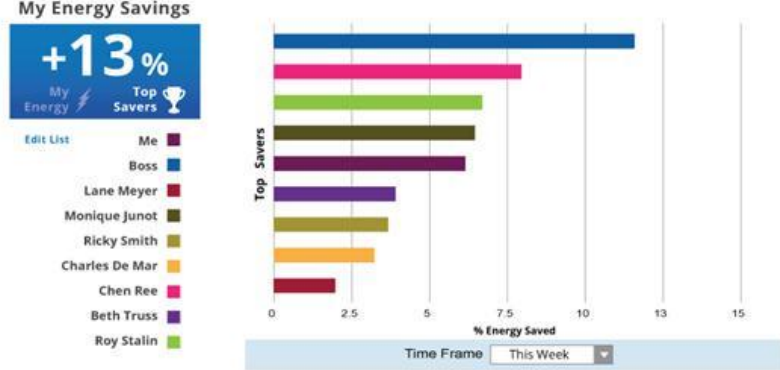


\section{My Energy Savings}

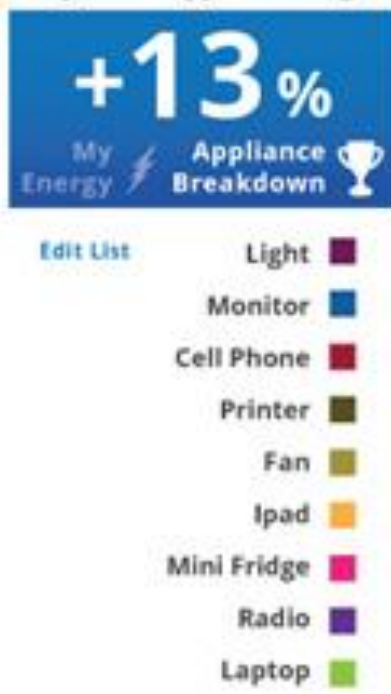

\section{Appliance Breakdown}

My Appliances

Boss

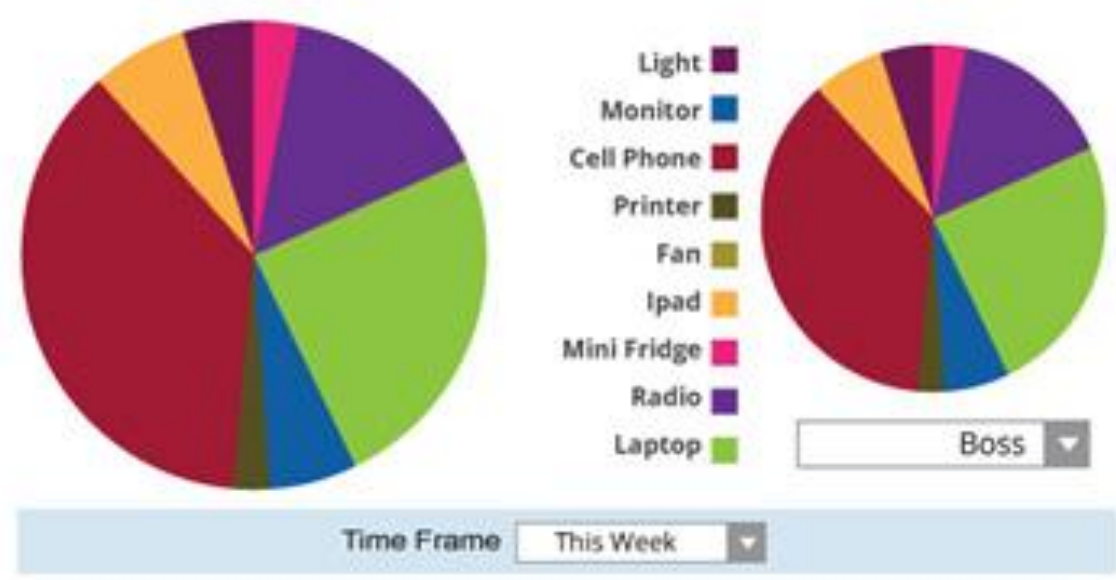


(a)

\begin{tabular}{|c|c|c|c|}
\hline My Friends & \multicolumn{3}{|c|}{ Expand $\mathrm{C}$} \\
\hline New ldea & & & \\
\hline \multicolumn{4}{|l|}{ Meg Thomas } \\
\hline Turned off the common lights & $\Delta 5$ & Q3 & $\checkmark 6$ \\
\hline \multicolumn{4}{|l|}{ Reggie Hall } \\
\hline Turned off the bathroom fights & $\Rightarrow 5$ & $Q 3$ & $\checkmark 6$ \\
\hline \multicolumn{4}{|l|}{ Ryan Reynolds } \\
\hline Turned off the common lights & $\$ 5$ & $Q^{3}$ & $\checkmark 6$ \\
\hline \multicolumn{4}{|l|}{ Meg Thomas } \\
\hline Turned off the bathroom lights & \$ 5 & Q3 & $\checkmark 6$ \\
\hline
\end{tabular}

(b)

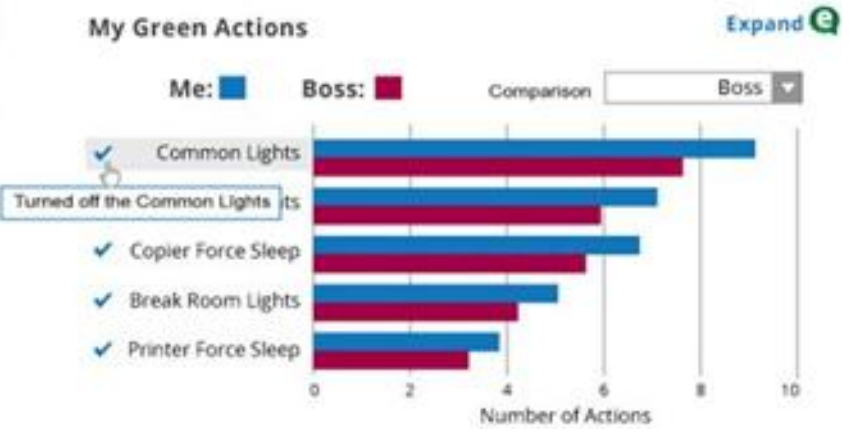


Table 1: Available graphical representations of energy consumption

\begin{tabular}{|c|c|c|}
\hline & Appliance Breakdown & Comparisons \\
\hline Individual View & $\begin{array}{l}\text { Relative energy-use of } \\
\text { appliances assigned to } \\
\text { user }\end{array}$ & $\begin{array}{l}\text { User energy-use comparisons } \\
\text { over time with members within } \\
\text { group or with friends }\end{array}$ \\
\hline Group View & $\begin{array}{l}\text { Relative energy-use of } \\
\text { each appliance type } \\
\text { summed across all } \\
\text { members of group }\end{array}$ & $\begin{array}{l}\text { Per capita energy-use } \\
\text { comparisons over time of user's } \\
\text { group with other groups }\end{array}$ \\
\hline
\end{tabular}


Table 2: List of Collected System Data

\begin{tabular}{ll} 
Data Point & Details \\
\hline User Logins & Timestamp of Login and User \\
Energy Visualization Preferences & Which plots were viewed in what time frame \\
Added Friends & Timestamp when user adds friend and friend's name \\
Energy Ranking View Instances & Timestamp when user views energy ranking \\
Eco-Action Center New Posts & Timestamp and text of post \\
Eco-Action Center Likes, Comments, Checks & Timestamp and text of associated post \\
Exposure to Goal & Boolean if user's group has an admin set goal \\
Ability to Add 'Friends' & Boolean if a user's group can add friends \\
Leader Presence & Boolean if user's group has leader assigned \\
Appliance Energy-Consumption & Appliance type and historical energy-use \\
Building Occupant Energy-Consumption & User's assigned appliances and total energy-use \\
User Organizational and Social Network Links & Number of network connections and user id's \\
Overall Organizational Structure & Group relationships and hierarchies \\
\hline
\end{tabular}

